\title{
Mitochondrial Localization of the Yeast Forkhead Factor Hcm1
}

\author{
María José Rodríguez Colman ${ }^{\dagger}$, Joaquim Ros (1) and Elisa Cabiscol * \\ Departament de Ciències Mèdiques Bàsiques, IRBLleida, Universitat de Lleida, 25198 Lleida, Spain; \\ M.J.RodriguezColman@umcutrecht.nl (M.J.R.C.); Joaquim.ros@udl.cat (J.R.) \\ * Correspondence: elisa.cabiscol@udl.cat; Tel.: +34-973-702-281 \\ + Current address: Molecular Cancer Research, Center for Molecular Medicine, University Utrecht, \\ 3584 CG Utrecht, The Netherlands.
}

Received: 26 November 2020; Accepted: 14 December 2020; Published: 16 December 2020

\begin{abstract}
Hcm} 1$ is a member of the forkhead transcription factor family involved in segregation, spindle pole dynamics, and budding in Saccharomyces cerevisiae. Our group described the role of Hcm1 in mitochondrial biogenesis and stress resistance, and in the cellular adaptation to mitochondrial respiratory metabolism when nutrients decrease. Regulation of $\mathrm{Hcm} 1$ activity occurs at the protein level, subcellular localization, and transcriptional activity. Here we report that the amount of protein increased in the G1/S transition phase when the factor accumulated in the nucleus. In the G2/M phases, the Hcm 1 amount decreased, and it was translocated outside the nucleus with a network-like localization. Preparation of highly purified mitochondria by a sucrose gradient density demonstrated that $\mathrm{Hcm} 1$ colocalized with mitochondrial markers, inducing expression of $C O X 1$, a mitochondrial encoded subunit of cytochrome oxidase, in the G2/M phases. Taken together, these results show a new localization of $\mathrm{Hcm} 1$ and suggest that it acts as a mitochondrial transcription factor regulating the metabolism of this organelle.
\end{abstract}

Keywords: forkhead transcription factor; Hcm1; mitochondria; cell cycle; mitochondrial metabolism; mtDNA; yeast

\section{Introduction}

To ensure the optimum adaptation of cells to environmental changes, a network of complex signaling pathways has evolved. Transcription factors play essential roles in controlling multiple cellular processes through gene expression regulation. In mammals, forkhead transcription factors (FKH-TFs) respond to a wide range of external stimuli such as nutrients and hormones like insulin, growth factors, neurotrophins, cytokines, and several stresses, including oxidative stress. FoxO transcription factors (FoxO1, 3, 4, and 6), a subfamily of FKH-TFs, control various biological functions including stress resistance, DNA repair, metabolism, cell cycle, and aging (reviewed in Refs. [1-3]). In accordance with such a variety of functions, their activity is regulated by phosphorylation, acetylation, ubiquitination, methylation, and glycosylation. A combination of these post-translational modifications controls FoxO protein levels, DNA-binding properties, and subcellular localization [3-5].

Saccharomyces cerevisiae has four members of the forkhead family of eukaryotic transcription factors (Fkh1, Fkh2, Fhl1, and Hcm1), classified on the basis of a conserved DNA-binding domain [6]. Hcm1 was first identified as a high copy suppressor of a defect in spindle pole assembly [7]. This cell-cycle-specific transcription factor was initially described to regulate the transcription of genes involved in chromosome organization, spindle dynamics, and budding [8]. It is periodically transcribed and functions as an S-phase-specific transcriptional activator [9]. Our group described that $\mathrm{Hcm} 1$ is also involved in mitochondrial biogenesis and stress resistance [10], and it plays a role in adaptation to respiratory 
metabolism in response to early nutrient limitation [11]. Moreover, it was found that $\mathrm{Hcm} 1$ controls life span independently of calorie restriction [12]. During aging, a rapid nuclear exclusion of $\mathrm{Hcm} 1$ leads to vacuolar alkalization and replicative senescence [13]. Regulation of Hcm1 activity occurs at several levels: gene expression, protein-protein interaction, post-translational modification, degradation, and subcellular localization [9-11,13-15].

Hcm1 interacts with Sir2, an NAD+-dependent histone deacetylase. In response to oxidative stress stimuli, sirtuin activity increases $\mathrm{Hcm} 1$ nuclear accumulation and, therefore, Hcm1-mediated gene expression involved in mitochondrial metabolism and oxidative stress resistance [10]. In fact, Fkh1 and Fkh2, whose expression is activated by Hcm1 [9], are also associated with Sir2 and coordinate a protective response against stress [16]. Hcm1 reacts both to glucose and nitrogen deficiency, participating in the metabolic shift from fermentation to respiration. In this context, the main kinases involved in nutrient response pathways (Snf1, Tor1, and Sch9) regulate $\mathrm{Hcm} 1$ transcriptional activity, with phosphorylation by Snf1 having a preponderant role [11].

In mammals, FoxO3 has been localized inside the nucleus, cytoplasm, as well as in the mitochondrial matrix and the mitochondrial outer membrane $[17,18]$. In yeast, Hcm 1 was the only FKH-TF found outside the nucleus. The localization of Hcm 1 in both the cytoplasm and nucleus was mentioned in a large-scale analysis of protein localization in budding yeast [19] and was also observed in previous studies from our group [10].

In this study, we report a new localization of the yeast Hcm1 in the mitochondria. In the G2/M phases, GFP-labeled Hcm 1 from synchronized cells showed a network-like structure outside the nucleus. Highly purified mitochondria reveal that this transcription factor colocalizes with mitochondrial markers, in agreement with the pattern observed by microscopy. Moreover, the mitochondrial encoded gene COX1 displays an Hcm1-dependent pattern with maximum expression in G2/M phases, supporting the role of $\mathrm{Hcm} 1$ as a mitochondrial transcription factor involved in activation of mitochondrial activity. These results are in line with $\mathrm{Hcm} 1$ acting as a nuclear regulator of mitochondrial respiration as previously described $[10,11]$.

\section{Results and Discussion}

\subsection{Cell Cycle Regulates Hom 1 Levels and Localization}

It is known that the yeast forkhead transcription factor HCM1 is periodically transcribed during the cell cycle [9]. In addition to HCM1 expression, we studied Hcm1 protein levels and localization through different phases of the cell cycle using alpha factor to synchronize the culture. Alpha factor stops the cell cycle at the end of the G1 phase. After release, cells resume growth synchronically [10]. Figure 1A,B shows that both mRNA and protein levels were highly regulated by the cell cycle, with maximum amounts in the late G1 and early $S$ phase (Figure 1C) when the transcription factor was concentrated in the nucleus (Figure 1D). Inside the nucleus it regulates the transcription of genes involved in chromosome segregation. Genes regulated by Hcm1 peak primarily during the late S phase [9]. Although chromosome segregation is impaired in the absence of Hcm1, budding kinetics under optimal growth conditions in $\Delta h c m 1$ cells is quite similar to wild-type cells [9]. In addition to this classical role, $\mathrm{Hcm} 1$ also participates in the adaptation of cells from fermentative to respiratory metabolism during nutrient scarcity. Hcm1 phosphorylation by Snf1 (sucrose-nonfermenting kinase), the founding member of the AMPK family, results in a shift from the cytoplasm to the nucleus and increased transcriptional activity of genes involved in respiration, use of alternative energy sources, NAD synthesis, and oxidative stress resistance [11]. Using GFP-labeled $\mathrm{Hcm} 1$ can reveal that, besides $\mathrm{Hcm} 1$ nuclear localization during the G1/S phases, $\mathrm{Hcm} 1$ also appeared with a network-like localization, which is clearly observed in the M phase (Figure 1E). Such a network structure resembles the mitochondrial organization observed in yeast [16]. 

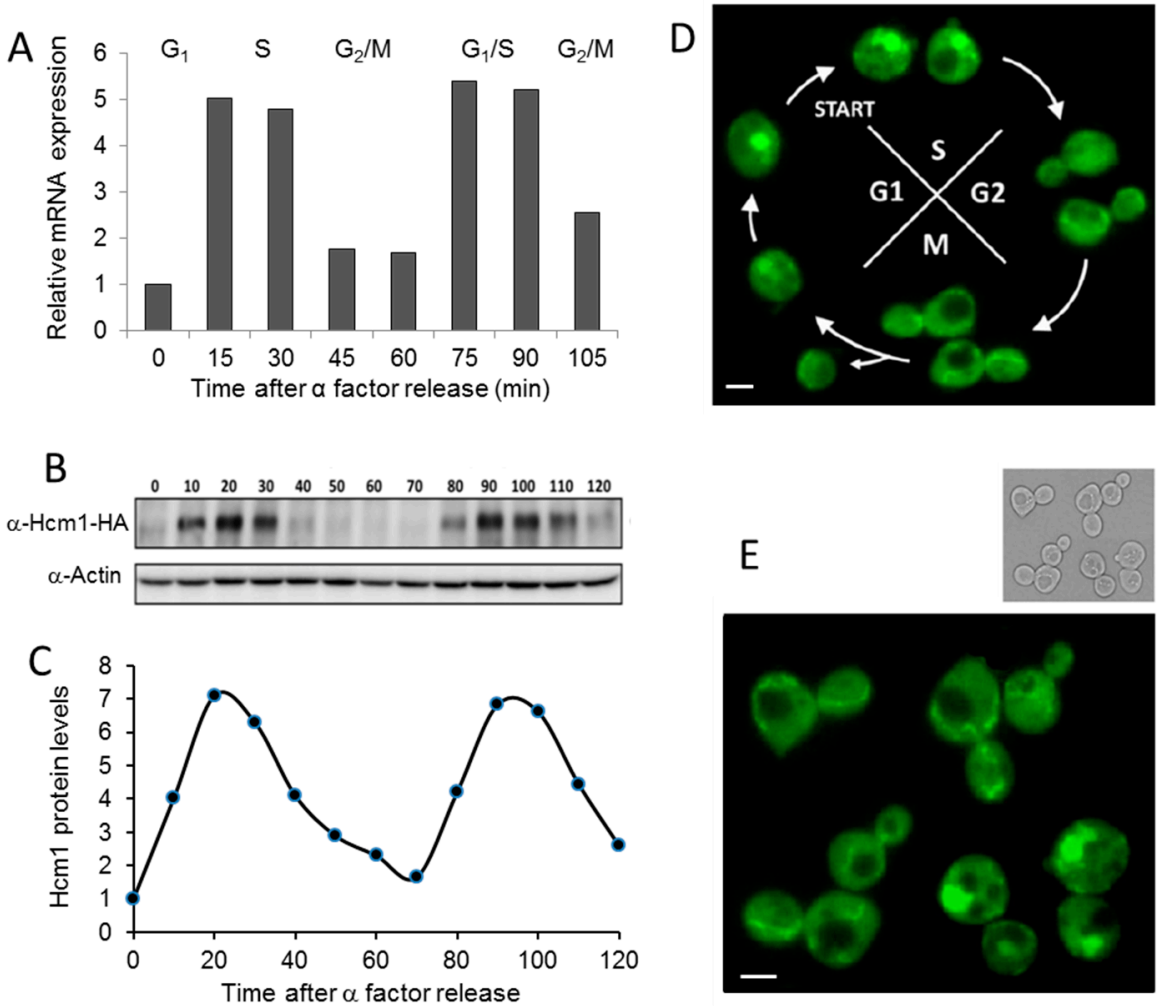

Figure 1. Cell cycle modulates the amount of $\mathrm{Hcm} 1$ and its localization. Cells grown exponentially were synchronized to G1 with $\alpha$-factor for $2 \mathrm{~h}$, and several parameters were determined at different times after release. (A) Hcm1 mRNA expression of WT (HCM1-HA) cells was determined by quantitative real-time PCR analysis. Actin expression was used as an internal control to normalize expression levels. (B) HA-tagged Hcm1 was analyzed by Western blot with anti-HA antibodies. Actin was used as a loading control. (C) Bands corresponding to $\mathrm{Hcm} 1$ in B were quantified, normalized by actin levels, and the relative intensities were calculated. (D) Pictures by fluorescence microscopy of HCM1-GFP cells were taken at different time points of the cell cycle. (E) Amplified fluorescent microscopy picture of several HCM1-GFP cells synchronized in the M phase. Scale bar, $1 \mu \mathrm{m}$.

\subsection{Mitochondrial Localization of Hcm1}

Having in mind that $\mathrm{Hcm} 1$ promotes mitochondrial biogenesis and is involved in oxidative metabolism [10], we explored the possibility that Hcm1 could shift from the nucleus to mitochondria in the G2/M phases. To this end, a cell extract fractionation was prepared to separate the cytosolic fraction from the mitochondrial-enriched fraction using exponentially grown WT (HCM1-HA) cells. Total, cytosolic, and mitochondrial-enriched fractions were analyzed by Western blot to detect $\mathrm{Hcm} 1$ localization. A mitochondrial protein (Hsp60) and a nuclear protein (Sir2) were also detected using specific antibodies and compared to Hcm1 (Figure 2A). Hsp60 appeared, as expected, in the total cell extract and in the mitochondrial-enriched fraction, with a pattern similar to that of Hcm1. As predicted, Sir2 only appeared in the total cell extract, containing the nuclei. Because endogenous levels of Hcm1 are very low (see Ref. [10] to compare with other yeast forkheads like Fkh1, Fkh2, and Fh11), an Hcm1-overexpressing strain was used. TetHCM1-HA cells were grown and cell extract fractionation was performed by differential centrifugation, as described in Materials and Methods. In this experiment, nuclear, cytosolic, and mitochondrial-enriched fractions were obtained. Figure 2B (lanes 1 to 6) shows Western blot images of anti-Hcm1, anti-V-ATPase, and anti-Dpm1. WT cells were submitted to the same procedure and used as a control (Figure 2B). In addition, to attain a sample with highly purified mitochondria, the mitochondrial-enriched fraction previously obtained was submitted to 
ultracentrifugation with a sucrose density gradient. Mitochondrial fractions were pooled, and proteins were detected by Western blot (Figure 2B, lanes 8 and 9).
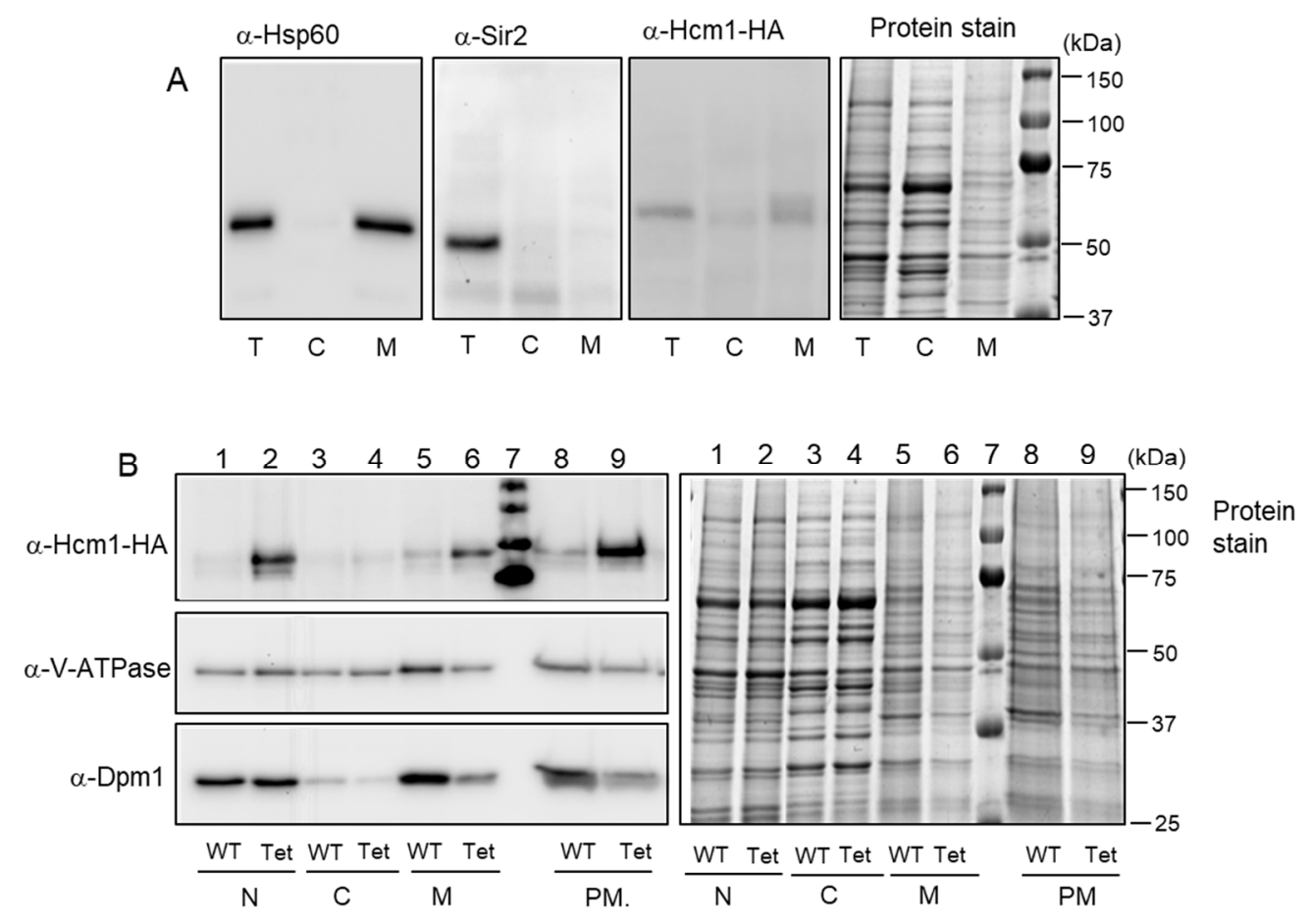

Figure 2. Analysis of $\mathrm{Hcm} 1$ localization by cell fractionation followed by sucrose-gradient centrifugation. (A) WT (HCM1-HA) cells growing exponentially were analyzed by Western blot of Hsp60 (mitochondrial protein), Sir2 (nuclear protein), and $\mathrm{Hcm} 1$ from total extracts and cytosolic and mitochondrial-enriched fractions. (B) WT (HCM1-HA) and Hcm1-overexpressing (tetHCM1-HA, labeled as tet) cells growing exponentially were fractionated in nuclear, cytosolic, and mitochondrial- enriched fractions (lanes 1 to 6). Mitochondrial-enriched fractions were subjected to a sucrose gradient centrifugation to obtain purified mitochondria (lanes 8 and 9). All samples were analyzed by Western blot with anti-HA (Hcm1), V-ATPase (vacuolar ATPase), and Dpm1 (ER dolichol-phosphate mannosyltransferase subunit 1 protein). Protein stain with Brilliant Coomassie Blue is shown as a loading control. T: total cell extract, C: cytosolic fraction, M: mitochondrial fraction, N: nuclear fraction, PM: purified mitochondria.

Overexpression of Hcm1 clearly showed that this transcription factor localized in the nucleus and also in the mitochondria. However, even highly purified mitochondria was contaminated with vacuolar and ER components. This is not unusual, since such structures are very difficult to fully split from mitochondria. To solve this problem and establish whether Hcm 1 was localized inside the mitochondria or associated with other contaminant organelles, the profile of this protein was analyzed through the total sucrose gradient and compared with the profiles of V-ATPase, Dpm1, and Por1. To that end, the mitochondrial-enriched fraction was loaded on top of a four-phase sucrose gradient $(60 \%, 32 \%, 23 \%$, and $15 \%)$ and centrifuged at $134,000 \times g$ for $60 \mathrm{~min}$. All gradient was collected in 11 fractions. Proteins were separated by SDS-PAGE and $\mathrm{Hcm} 1$ plus the marker proteins, detected by Western blot (Figure 3A). Bands were quantified from each fraction, and the relative amounts are shown in Figure 3B. The vacuolar marker, V-ATPase, was detected throughout the entire gradient, with enrichment in fractions 5 to 9. Dpm1, the ER marker, was also detected along the whole gradient, with a maximum from fractions 6 to 11. In the case of the mitochondrial marker Por1, it could be noticed starting at fraction 4 and enriched from fractions 6 to 10. As can be seen in Figure 3B, the Hcm1 profile closely resembled that of mitochondrial Por1. The Hcm1 profile did not match with the vacuolar marker or the ER marker, although differences with Dpm1 were not as clear as with V-ATPase. 


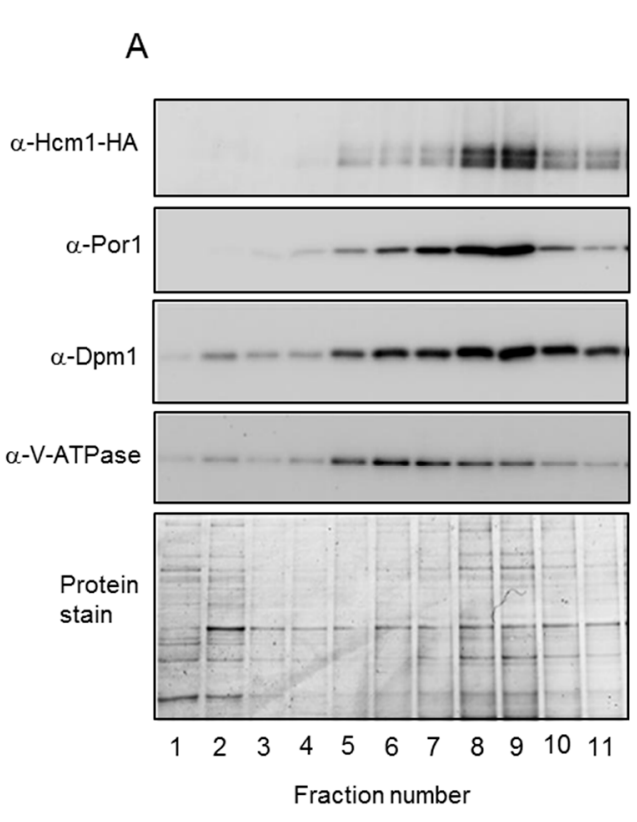

B
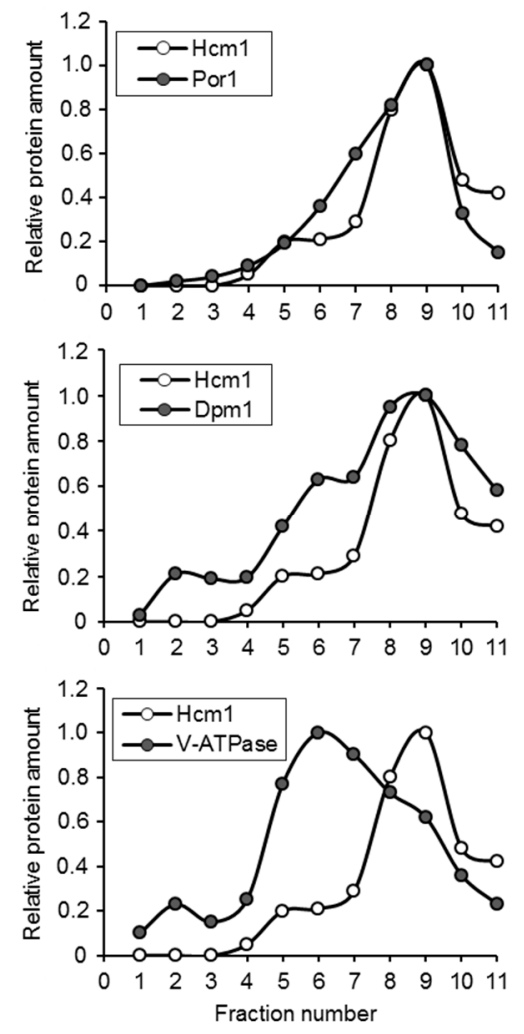

Figure 3. Fraction analysis of the sucrose gradient centrifugation used in mitochondrial purification. (A) Mitochondrial-enriched fractions from tetHCM1-HA cells were separated by four-phase sucrose gradient centrifugation. The distribution of $\mathrm{Hcm} 1$ was analyzed in each fraction by Western blot with anti-HA. Western blot anti-porin (mitochondria), anti-V-ATPase (vacuole), and anti-Dpm1 (ER) were used as markers of these organelles. Fractions 1 to 11 represent the top and the bottom of the sucrose density gradient, respectively. Protein stain with Brilliant Coomassie Blue is shown as a loading control. (B) Bands corresponding to Hcm1, porin, V-TPase, and Dpm1 in A were quantified. In each image, the fraction with the highest value was normalized to 1 .

V-ATPase is encoded by the VMA2 gene and is the $\beta$ subunit of the eight subunits that constitute the membrane domain of V-ATPase. This protein acts as a proton pump located in the cellular endomembrane system [20], but its localization is mostly vacuolar [21]. On the other hand, Dpm1 corresponds to a dolichol mannose phosphate synthetase. This enzyme exerts its activity on the cytosolic face of the endoplasmic reticulum (ER), and the modified sugar enters the lumen of the reticulum [22]. Like the vacuolar marker (V-ATPase), Dpm1 is also a membrane protein. The porin Por1 was used as a mitochondrial marker. Por1 is a voltage-gated anion channel that is located in the mitochondrial outer membrane. This protein participates in the osmotic stability and permeability of the mitochondria $[23,24]$.

It is common for cell homogenization to result in the rupture of large structures such as the ER and perhaps also vacuoles. This rupture may generate fragments of membranes that would reassemble into structures with density similar to mitochondria and, as a consequence, co-purify with this organelle. In addition, it must be considered that the ER is part of the yeast endomembrane system that surrounds many organelles and encompasses a large portion of the cell [25]. Thus, it seems unlikely that mitochondria could be exclusively isolated without dragging any membranous portion of the reticulum. Taken together, these results highly suggest that after nuclear exclusion in the G2/M phases, Hcm1 showed a mitochondrial localization with a network-like structure. However, the possibility that Hcm1 could be located in mitochondria-associated membranes (MAM), a region of the ER reversibly tethered to mitochondria, cannot be completely dismissed. 


\subsection{Hcm1, mtDNA Copy Number, and Mitochondrial Gene Activation}

$\mathrm{Hcm} 1$ is involved in mitochondrial metabolism, since cells overexpressing Hcm1 display increased levels of mitochondrial proteins and oxygen consumption [10]. To obtain further evidence, the mitochondrial DNA (mtDNA) copy number was measured. mtDNA is quantified by the ratio between a target mitochondrial gene and a reference nuclear gene (mtDNA/nDNA) using quantitative real-time PCR. To that end, total DNA was used to amplify the mitochondrial COX1 gene and the nuclear ACT1 gene in a simultaneous reaction. As shown in Figure 4, the mtDNA copy number was much higher in tetHCM1-HA cells and slightly lower (but not statistically significant) in $\Delta h \mathrm{~cm} 1$ cells, compared to WT cells. Thus, Hcm1 levels correlated to mitochondrial abundance.

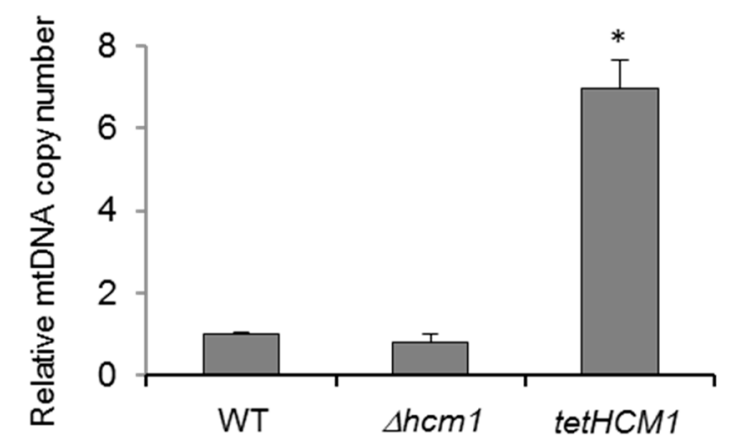

Figure 4. Hcm1 and mtDNA copy number. The number of copies of mtDNA was normalized by the number of copies of nDNA as described in Materials and Methods. COX1 was used as a target mitochondrial gene, and ACT1 was used as the reference nuclear gene. Gene amplification was carried out by real-time qPCR in a duplex reaction from total DNA from the indicated strains. Statistical analysis was performed comparing mutants with WT cells. The data are represented as the means \pm SD from at least three independent experiments. ${ }^{*} p<0.01$.

However, such results did not directly imply a role of $\mathrm{Hcm} 1$ inside the mitochondria. To explore further, expressions of two genes throughout the cell cycle were measured in WT and $\Delta h c m 1$ synchronized cells. They were PUT1, a nuclear gene known to be directly regulated by Hcm1 [10], and COX1, a mitochondrial gene with a potential Hcm1-binding site [9] (Figure 5A). PUT1, coding for the enzyme proline oxidase, is needed to use proline in the mitochondria as an energy source when nutrients are scarce [11]. The COX1 gene encodes the Cox1 subunit, which, together with Cox 2 and Cox3, compose the core of the cytochrome oxidase complex, the last electron acceptor in the mitochondrial respiratory chain. PUT1 and COX1 showed a cell-cycle-dependent expression pattern, which was abolished in $\Delta h c m 1$ cells (Figure $5 \mathrm{~B}, \mathrm{C}$ ). As a negative control, we evaluated the expression of $A D H 1$, a nuclear gene coding for the cytosolic enzyme alcohol dehydrogenase 1 with no Hcm1-binding site in its promoter. As expected, $A D H 1$ expression was unaffected in $\Delta h c m 1$ cells (Figure 5D). Interestingly, the expression profiles of the PUT1 and COX1 genes were almost opposite. PUT1 followed a pattern similar to $\mathrm{Hcm} 1$ that was slightly delayed in time (compare Figure 5B with Figure 5C). This is in agreement with the nuclear localization of $\mathrm{Hcm} 1$ and its role as a transcription activator of nuclear genes $[9,11]$. The expression profile of the mitochondrial COX1 showed a maximum in the G2/M phases (Figure 5C), when Hcm1 was found outside the nucleus. Such a specific pattern of COX1 expression that is Hcm1-dependent and coincides with the mitochondrial localization of Hcm1 supports the role of $\mathrm{Hcm} 1$ acting as a mitochondrial transcription factor. This role would be similar to that described for mammalian FoxO3. A low-glucose regimen induces the formation of a FoxO3A, SirT3, and mitochondrial RNA polymerase complex, causing activation of the mitochondrial genome and a subsequent increase in mitochondrial respiration [13]. Likewise, in metabolically stressed cancer cells, ERK and AMPK activation induce mitochondrial translocation of FoxO3 and expression of the mitochondrial genome to support mitochondrial metabolism [18]. In this condition, FoxO3 was also localized in the mitochondrial outer membrane. Although we cannot rule out $\mathrm{Hcm} 1$ being associated 
with the mitochondria or any membranous structure associated with mitochondria, the fact that mitochondrial localization in the G2/M phases coincided with COX1 gene expression reinforces the role of $\mathrm{Hcm} 1$ as a mitochondrial transcriptional activator.

A

Consensus $\mathrm{Hcm} 1$-binding site
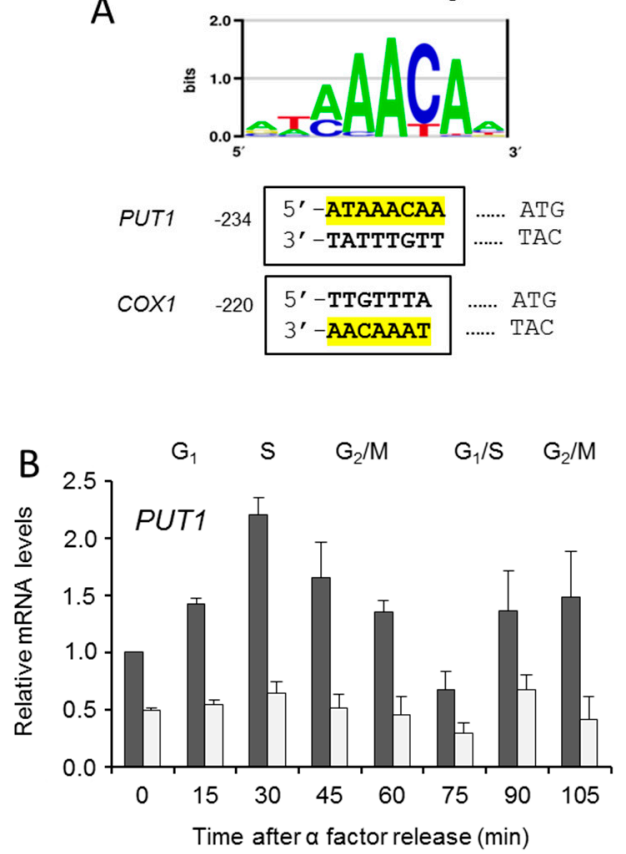
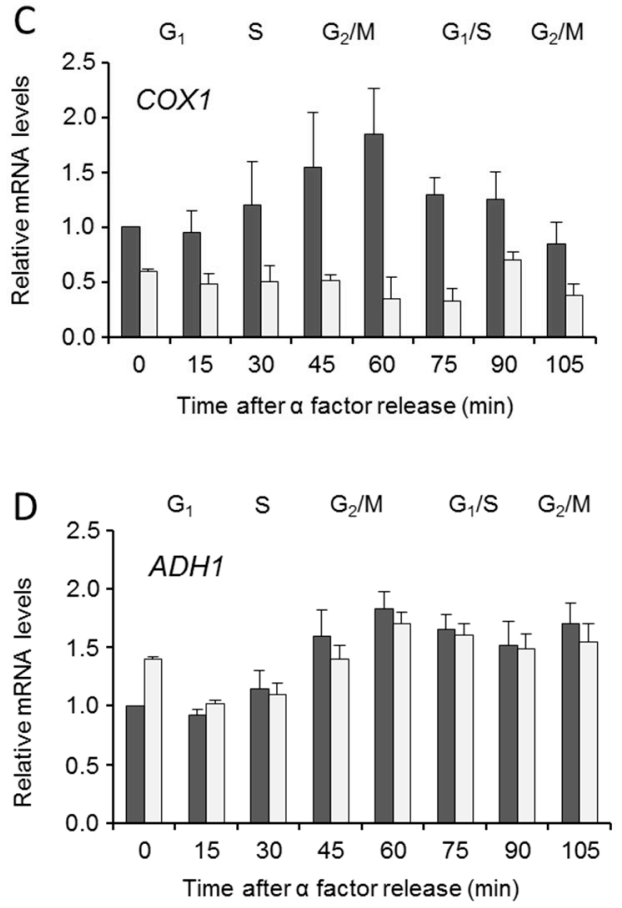

Figure 5. Hcm1-dependent gene expression and cell cycle. (A) Consensus binding motifs for Hcm1 in the promoter regions of PUT1 and COX1. COX1 motif was found on the Crick strand (http://yetfasco.ccbr.utoronto.ca) [26]. WT and $\Delta h c m 1$ cells grown exponentially were synchronized to $\mathrm{G} 1$ with $\alpha$-factor for $2 \mathrm{~h}$, and mRNA of genes were determined by quantitative real-time PCR analysis at different times after release. (B) mRNA expression of PUT1, a nuclear encoded gene. (C) mRNA expression of COX1, a mitochondrial encoded gene. (D) mRNA expression of ADH1, a nuclear encoded gene used as a control. The data are represented as the means \pm SD from at least three independent experiments.

In conclusion, our results point, for the first time, at the mitochondrial localization of $\mathrm{Hcm} 1$. Furthermore, our data suggest that $\mathrm{Hcm} 1$ translocates from nucleus to mitochondria in the G2/M phases and induces expression of mitochondrial encoded genes, such as COX1, favoring mitochondrial metabolism. Although further functional studies are required to fully elucidate the mitochondrial role of Hcm1, these results are in accordance with $\mathrm{Hcm} 1$ acting in coordination both as a mitochondrial and nuclear activator involved in mitochondrial respiratory metabolism and stress resistance. They also define $\mathrm{Hcm} 1$ as a key player to adapt yeast cells to nutrient scarcity.

\section{Materials and Methods}

\subsection{Yeast Strains and Growth Conditions}

S. cerevisiae strains used in this work are listed in Supplementary Table S1. All strains employed in this work derived from CML128 (MATa ura3-52 his4 leu2-3,112 trp1) [27]. A HA-tagged Hcm1 strain, HCM1-HA, was used as a WT strain. For microscopic studies, a GFP-tagged Hcm1 strain was used. HA and GFP were C-terminally labeled [10]. Null mutant $\Delta h c m 1$ was obtained by using the short flanking homology approach after PCR amplification of the natMX4 cassette. Disruption was confirmed by PCR analysis. Overexpression of the Hcm1 protein TetHCM1-HA was obtained by replacing the endogenous promoter with a tet $\mathrm{O}_{7}$ promoter as described [28]. The cells were grown at 
$30{ }^{\circ} \mathrm{C}$ by incubation in a rotary shaker at $180 \mathrm{rpm}$ using YPD medium ( $1 \%$ yeast extract, $2 \%$ peptone, $2 \%$ glucose).

\subsection{Cell Extracts Fractionation and Mitochondria Purification}

To obtain mitochondrial enriched fractions, yeast cells (2 OD) grown in YPD to an $\mathrm{A}_{600}=1$ were centrifuged and resuspended with $100 \mathrm{mM}$ Tris- $\mathrm{HCl}$ pH 9.4, $10 \mathrm{mM}$ DTT. After 20 min incubation at $30^{\circ} \mathrm{C}$, cells were centrifuged at $3000 \times g$ for $5 \mathrm{~min}$, and the supernatant was discarded. Cells were washed in a $20 \mathrm{mM}$ sodium phosphate buffer, $\mathrm{pH}$ 7.4, 1.2 M sorbitol, and resuspended in the same buffer plus zymolyase to remove the cell wall. After $30-45 \mathrm{~min}$ incubation at $30^{\circ} \mathrm{C}$, spheroplast were centrifuged at $3000 \times \mathrm{g}$ for $5 \mathrm{~min}$, washed in $20 \mathrm{mM}$ sodium phosphate buffer, $\mathrm{pH} 7.4,1.2 \mathrm{M}$ sorbitol, and resuspended in $10 \mathrm{mM}$ Tris- $\mathrm{HCl} \mathrm{pH} 7.4,0.6 \mathrm{M}$ sorbitol, $1 \mathrm{mM}$ EDTA, $0.2 \%(w / v)$ BSA, and protease inhibitors. Spheroplasts were homogenized with a Dounce homogenizer (Sigma-Aldrich, Madrid, Spain) and centrifuged at $4000 \times g$ for $5 \mathrm{~min}$. Nucleus and cell debris were pelleted, and the supernatant solution containing the cytosolic plus the mitochondrial fraction was centrifuged again at $12,000 \times g$ for $15 \mathrm{~min}$. The pellet containing the enriched mitochondrial fraction was resuspended in a $10 \mathrm{mM}$ MOPS-KOH buffer pH 7.2, $250 \mathrm{mM}$ sucrose, 1 mM EDTA. Samples were either used as such for Western blot or used for further purification to obtain highly purified mitochondria.

Highly pure fractions of mitochondria were obtained as described [29] with some modifications. In brief, a four-phase sucrose gradient $(60 \%, 32 \%, 23 \%$, and $15 \%)$ was prepared in an ultracentrifuge tube (total volume of $4.5 \mathrm{~mL}$ ). From 100 to $500 \mu \mathrm{L}$ of enriched mitochondrial fraction (at $5 \mathrm{mg} / \mathrm{mL}$ ) was carefully loaded on top of the gradient and centrifuged at $134,000 \times g$ for $60 \mathrm{~min}$ at $4{ }^{\circ} \mathrm{C}$. All gradient was collected in $500 \mu \mathrm{L}$ fractions, and each fraction was diluted with $1 \mathrm{~mL}$ of $10 \mathrm{mM} \mathrm{MOPS-KOH}$ buffer $\mathrm{pH}$ 7.2, $250 \mathrm{mM}$ sucrose, $1 \mathrm{mM}$ EDTA. Mitochondria and other organelles were pelleted by centrifugation at $10,000 \times g$ and resuspended in $32 \mu \mathrm{L}$ of $10 \mathrm{mM}$ MOPS-KOH buffer $\mathrm{pH} 7.2,250 \mathrm{mM}$ sucrose, $1 \mathrm{mM}$ EDTA plus $8 \mu \mathrm{L}$ of loading buffer ( $375 \mathrm{mM}$ Tris- $\mathrm{HCl} \mathrm{pH} \mathrm{6.5,10 \%} \mathrm{SDS,} \mathrm{25 \%} \beta$-mercaptoethanol, $50 \%$ glycerol, $6 \mathrm{mM}$ bromophenol blue). Samples were finally incubated for $5 \mathrm{~min}$ at $95{ }^{\circ} \mathrm{C}$ before SDS-PAGE.

\subsection{Yeast Cell Synchronization}

The cells were synchronized by a block and release protocol ( $\alpha$-factor treatment). The cultures were grown to an $\mathrm{A}_{600}=0.75$ in YPD, and $\alpha$-factor (Gene Script Biotech, Leiden, The Netherlands, ref RP01002) was added to a concentration of $5 \mu \mathrm{g} / \mathrm{mL}$. After $45 \mathrm{~min}, \alpha$-factor was added again to a final concentration of $10 \mu \mathrm{g} / \mathrm{mL}$. After $90 \mathrm{~min}$, synchronized cells in G1 were checked by visualization of nonbudded cells by contrast microscopy. Alpha-factor was removed by pelleting the cells for $4 \mathrm{~min}$ at $4000 \mathrm{rpm}$ at $4{ }^{\circ} \mathrm{C}$. The cells were washed once with cold YPD. G1-arrested cells were resuspended in fresh YPD when indicated. Samples were taken every $15 \mathrm{~min}$ for gene expression analysis by qPCR.

\subsection{Gene Expression Analysis}

Quantitative real-time PCR (RT-PCR) was performed using the TaqMan System (Applied Biosystems, Thermo Fisher Scientific, Waltham, MA, USA) [30]. Total RNA was extracted using the RNeasy kit (Qiagen, Barcelona, Spain ref. 74104) according to the manufacturer's instructions, and $1 \mu \mathrm{g}$ total RNA from each sample was converted into cDNA with $50 \mathrm{ng}$ utilized for each individual RT-PCR assay in a 48-cycle, three-step PCR reaction using the iCycler (Bio-Rad, Alcobendas, Madrid, Spain). Amplification was performed using the TaqMan Universal PCR Master Mix kit (Applied Biosystems, Thermo Fisher Scientific, Waltham, MA, USA, Cat. 4304437). Quantification was completed using iCycler IQ Real-Time detection system software (version 2.3, Bio-Rad, Alcobendas, Madrid, Spain). For all gene expression analyses, actin (ACT1) was used as an internal control. Data represent at least three technical repeats of each analysis.

An mtDNA copy number was normalized versus a nuclear DNA copy number. To this end, the COX1 gene was amplified by real-time PCR as a measure of the mitochondrial DNA index, and the ACT1 gene was amplified as the nuclear DNA index. Both amplifications were carried out at the same 
time in the same well because the Taqman probes are made with different fluorophores (VIC for ACT1 and FAM for COX1) and can be detected in distant fluorescence channels. The reactions were carried out from total DNA, in quadruplicate and in a final volume of $20 \mu \mathrm{L}$. The reagents used were the same as described above. Statistical analysis was performed using the Student's $t$ test.

All RNAs were analyzed using predesigned Taqman Gene Expression Assays from Life Technologies (Thermo Fisher Scientific, Waltham, MA, USA). References: HCM1: Sc04105445_s1; ADH1: Sc04163599_s1; PUT1: Sc04147047_s1; COX1: Sc04164539_s1; ACT1: Sc04120488_s1.

\subsection{Western Blot Analysis}

Cell extracts were obtained as described [31], separated in SDS-PAGE, and transferred to polyvinylidene difluoride membranes (Immobilon-P, Millipore, Mollet del Vallès, Spain). Anti-HA (1:2500 dilution, from Roche, Sant Cugat, Spain or Biolegend, San Diego, CA, USA, ref. 1-867-423), anti-actin (1:2000 dilution, from Chemicon, Thermo Fisher Scientific, Waltham, MA, USA, ref. MAB1501R), anti-Hsp60 (1:6000 dilution, from StressGen, San Diego, CA, USA, ref. SPA808), anti-Sir2 (1:11,000 dilution, from Santa Cruz Biotechnology Inc., Heidelberg, Germany, ref. SC-6666), anti-Por1 (1:1000 dilution, from Molecular Probes, Thermo Fisher Scientific, Waltham, MA, USA, ref. A6449), anti-Dpm1 (1:250 dilution, from Invitrogen, Thermo Fisher Scientific, Waltham, MA, USA, ref. A6429), and anti V-ATPase (1:4000 dilution, from Invitrogen, Thermo Fisher Scientific, Waltham, MA, USA, ref. A6427) were used as primary antibodies. The secondary antibodies conjugated to horseradish peroxidase were used as follows: goat anti-mouse antibody (1:40,000 dilution, from Pierce, Thermo Fisher Scientific, Waltham, MA, USA, ref. 31430), goat anti-rat (1:4000 dilution, from Molecular Probes, Thermo Fisher Scientific, Waltham, MA, USA, ref. A10549), and rabbit anti-goat (1:25,000 dilution, from Thermo Fisher Scientific Sci., Waltham, MA, USA, ref. A10549). Images were acquired in a ChemiDoc XRS System (Bio-Rad, Alcobendas, Madrid, Spain) and analyzed with Quantity One software (Bio-Rad, Alcobendas, Madrid, Spain).

\subsection{Microscopy Studies}

At different times after $\alpha$-factor synchronization, HCM1-GFP-labeled cells grown in YPD medium (0.5 ODs) were centrifuged at $3000 \times g$ for $3 \mathrm{~min}$ and resuspended in $40 \mu \mathrm{L}$ of $20 \mathrm{mM}$ sodium phosphate buffer, pH 7.4. Cells were analyzed by fluorescence microscopy (Olympus DP30 BW, L'Hospitalet de Llobregat, Spain) using $488 \mathrm{~nm}$ laser excitation for GFP, and pictures were taken. Fluorescent images were adjusted to better visualize localization.

Supplementary Materials: Supplementary materials can be found at http:/www.mdpi.com/1422-0067/21/24/ 9574/s1.

Author Contributions: Conceptualization, M.J.R.C., J.R. and E.C.; Data curation, M.J.R.C. and E.C.; Funding acquisition, J.R. and E.C.; Investigation, M.J.R.C., J.R. and E.C.; Project administration, J.R. and E.C.; Supervision, M.J.R.C., J.R. and E.C. Writing—original draft, E.C.; Writing—review \& editing, M.J.R.C., J.R. and E.C. All authors have read and agreed to the published version of the manuscript.

Funding: This research was funded by Ministerio de Ciencia e Innovación (Spain), grants BFU2010-17387 and CSD2007-20 Consolider Ingenio.

Acknowledgments: We thank Roser Pané for technical assistance.

Conflicts of Interest: The authors declare no conflict of interest.

\section{Abbreviations}

$\begin{array}{ll}\text { FKH-TF } & \text { Forkhead transcription factor } \\ \text { ER } & \text { Endoplasmic reticulum } \\ \text { mtDNA } & \text { Mitochondrial DNA } \\ \text { nDNA } & \text { Nuclear DNA }\end{array}$




\section{References}

1. Martins, R.S.T.; Lithgow, G.J.; Link, W. Long live FOXO: Unraveling the role of FOXO proteins in aging and longevity. Aging Cell 2016, 15, 196-207. [CrossRef] [PubMed]

2. Hagenbuchner, J.; Ausserlechner, M.J. Mitochondria and FOXO3: Breath or die. Front. Physiol. 2013, 4, 147. [CrossRef] [PubMed]

3. Calnan, D.R.; Brunet, A. The FoxO code. Oncogene 2008, 27, 2276-2288. [CrossRef] [PubMed]

4. Link, W. Introduction to FOXO Biology. Methods Mol. Biol. 2019, 1890, 1-9. [CrossRef]

5. Brown, A.K.; Webb, A.E. Regulation of FOXO Factors in Mammalian Cells. Curr. Top. Dev. Biol. 2018, 127, 165-192. [CrossRef]

6. Kaestner, K.H.; Knochel, W.; Martinez, D.E. Unified nomenclature for the winged helix/forkhead transcription factors. Genes Dev. 2000, 14, 142-146.

7. Zhu, G.; Muller, E.G.; Amacher, S.L.; Northrop, J.L.; Davis, T.N. A dosage-dependent suppressor of a temperature-sensitive calmodulin mutant encodes a protein related to the fork head family of DNA-binding proteins. Mol. Cell. Biol. 1993, 13, 1779-1787. [CrossRef]

8. Horak, C.E.; Luscombe, N.M.; Qian, J.; Bertone, P.; Piccirrillo, S.; Gerstein, M.; Snyder, M. Complex transcriptional circuitry at the G1/S transition in Saccharomyces cerevisiae. Genes Dev. 2002, 16, 3017-3033. [CrossRef]

9. Pramila, T. The Forkhead transcription factor Hcm1 regulates chromosome segregation genes and fills the S-phase gap in the transcriptional circuitry of the cell cycle. Genes Dev. 2006, 20, 2266-2278. [CrossRef]

10. Rodriguez-Colman, M.J.; Reverter-Branchat, G.; Sorolla, M.A.; Tamarit, J.; Ros, J.; Cabiscol, E. The Forkhead Transcription Factor Hcm1 Promotes Mitochondrial Biogenesis and Stress Resistance in Yeast. J. Biol. Chem. 2010, 285, 37092-37101. [CrossRef]

11. Rodríguez-Colman, M.J.; Sorolla, M.A.; Vall-Llaura, N.; Tamarit, J.; Ros, J.; Cabiscol, E. The FOX transcription factor Hcm1 regulates oxidative metabolism in response to early nutrient limitation in yeast. Role of Snf1 and Tor1/Sch9 kinases. Biochim. Biophys. Acta (BBA) Bioenerg. 2013, 1833, 2004-2015. [CrossRef] [PubMed]

12. Maoz, N.; Gabay, O.; Ben-Asher, H.W.; Cohen, H.Y. The Yeast Forkhead HCM1 Controls Life Span Independent of Calorie Restriction. J. Gerontol. Ser. A Boil. Sci. Med. Sci. 2014, 70, 444-453. [CrossRef] [PubMed]

13. Ghavidel, A.; Baxi, K.; Prusinkiewicz, M.; Swan, C.; Belak, Z.R.; Eskiw, C.H.; Carvalho, C.E.; Harkness, T.A. Rapid Nuclear Exclusion of Hcm1 in AgingSaccharomyces cerevisiaeLeads to Vacuolar Alkalization and Replicative Senescence. G3 Genes Genomes Genet. 2018, 8, 1579-1592. [CrossRef] [PubMed]

14. Negishi, T.; Veis, J.; Hollenstein, D.M.; Sekiya, M.; Ammerer, G.; Ohya, Y. The Late S-Phase Transcription Factor Hcm1 Is Regulated through Phosphorylation by the Cell Wall Integrity Checkpoint. Mol. Cell. Biol. 2016, 36, 941-953. [CrossRef] [PubMed]

15. Arsenault, H.E.; Roy, J.; Mapa, C.E.; Cyert, M.S.; Benanti, J.A. Hcm1 integrates signals from Cdk1 and calcineurin to control cell proliferation. Mol. Biol. Cell 2015, 26, 3570-3577. [CrossRef] [PubMed]

16. Linke, C.; Klipp, E.; Lehrach, H.; Barberis, M.; Krobitsch, S. Fkh1 and Fkh2 associate with Sir2 to control CLB2 transcription under normal and oxidative stress conditions. Front. Physiol. 2013, 4, 173. [CrossRef]

17. Peserico, A.; Chiacchiera, F.; Grossi, V.; Matrone, A.; Latorre, D.; Simonatto, M.; Fusella, A.; Ryall, J.G.; Finley, L.W.S.; Haigis, M.C.; et al. A novel AMPK-dependent FoxO3A-SIRT3 intramitochondrial complex sensing glucose levels. Cell. Mol. Life Sci. 2013, 70, 2015-2029. [CrossRef]

18. Celestini, V.; Tezil, T.; Russo, L.; Fasano, C.; Sanese, P.; Forte, G.; Peserico, A.; Signorile, M.L.; Longo, G.; De Rasmo, D.; et al. Uncoupling FoxO3A mitochondrial and nuclear functions in cancer cells undergoing metabolic stress and chemotherapy. Cell Death Dis. 2018, 9, 231. [CrossRef]

19. Ghaemmaghami, S.; Huh, W.-K.; Bower, K.; Howson, R.W.; Belle, A.; Dephoure, N.; O'Shea, E.K.; Weissman, J.S. Global analysis of protein expression in yeast. Nat. Cell Biol. 2003, 425, 737-741. [CrossRef]

20. Forgac, M. Structure and properties of the clathrin-coated vesicle and yeast vacuolar V-ATPases. J. Bioenerg. Biomembr. 1999, 31, 57-65. [CrossRef]

21. Kane, P.M.; Kuehn, M.C.; Howald-Stevenson, I.; Stevens, T.H. Assembly and targeting of peripheral and integral membrane subunits of the yeast vacuolar H(+)-ATPase. J. Biol. Chem. 1992, 267, 447-454. [PubMed]

22. Orlean, P. Dolichol phosphate mannose synthase is required in vivo for glycosyl phosphatidylinositol membrane anchoring, $\mathrm{O}$ mannosylation, and $\mathrm{N}$ glycosylation of protein in Saccharomyces cerevisiae. Mol. Cell. Biol. 1990, 10, 5796-5805. [CrossRef] [PubMed] 
23. Lee, A.; Xu, X.; Blachly-Dyson, E.; Forte, M.; Colombini, M. The role of yeast VDAC genes on the permeability of the mitochondrial outer membrane. J. Membr. Biol. 1998, 161, 173-181. [CrossRef] [PubMed]

24. Sánchez, N.S.; Pearce, D.A.; Cardillo, T.S.; Uribe, S.; Sherman, F. Requirements of Cyc2p and the Porin, Por1p, for Ionic Stability and Mitochondrial Integrity in Saccharomyces cerevisiae. Arch. Biochem. Biophys. 2001, 392, 326-332. [CrossRef]

25. Grissom, J.H.; Segarra, V.A.; Chi, R.J. New Perspectives on SNARE Function in the Yeast Minimal Endomembrane System. Genes 2020, 11, 899. [CrossRef] [PubMed]

26. Lis, M.; Walther, D. The orientation of transcription factor binding site motifs in gene promoter regions: Does it matter? BMC Genom. 2016, 17, 185. [CrossRef]

27. Gallego, C.; Garí, E.; Colomina, N.; Herrero, E.; Aldea, M. The Cln3 cyclin is down-regulated by translational repression and degradation during the $\mathrm{G} 1$ arrest caused by nitrogen deprivation in budding yeast. EMBO J. 1997, 16, 7196-7206. [CrossRef]

28. Goldstein, A.L.; McCusker, J.H. Three new dominant drug resistance cassettes for gene disruption in Saccharomyces cerevisiae. Yeast 1999, 15, 1541-1553. [CrossRef]

29. Meisinger, C.; Pfanner, N.; Truscott, K.N.; Xiao, W. Isolation of Yeast Mitochondria; Humana Press: New Jersey, NJ, USA, 2006; pp. 33-40. [CrossRef]

30. Vall-Llaura, N.; Mir, N.; Garrido, L.; Vived, C.; Cabiscol, E. Redox control of yeast Sir2 activity is involved in acetic acid resistance and longevity. Redox Biol. 2019, 24, 101229. [CrossRef]

31. Reverter-Branchat, G.; Cabiscol, E.; Tamarit, J.; Sorolla, M.A.; De La Torre-Ruiz, M.A.; Ros, J. Chronological and replicative life-span extension in Saccharomyces cerevisiae by increased dosage of alcohol dehydrogenase 1. Microbiology 2007, 153, 3667-3676. [CrossRef] [PubMed]

Publisher's Note: MDPI stays neutral with regard to jurisdictional claims in published maps and institutional affiliations. 